\section{Verônica e sua autonomia}

Flávia Biroli. Autonomia e desigualdades de gênero: contribuiçôes do feminismo para a crítica democrática. Vinhedo, Horizonte, 2013. 208 páginas.

\section{José Szwako}

Paulistana, Verônica tem pouco mais de 30 anos; foi para a Espanha depois de ter deixado uma faculdade e após ter trabalhado como prostituta "de alto nível” ainda em São Paulo. À diferença de outras brasileiras, a viagem de Verônica para a Europa envolveu centralmente a contração de uma dívida. Nisso ela difere tanto de quem se desloca transnacionalmente com a "ajuda" de redes informais de familiares e afins (com fins expressos voltados para quaisquer mercados, entre eles o mercado sexual) como daqueles casos, especificamente ligados à prostituição, nos quais "a viagem é realizada de forma voluntária e autônoma. Não envolve dívidas nem um amplo número de intermediários" (Piscitelli, 2012, p. 291). Em entrevista, Verônica disse que deixou o clube no qual trabalhava na Andaluzia e que o julgava inseguro especialmente por ter passado por uma situação traumática na qual um homem tentou matá-la, tendo sido posteriormente preso. Em Barcelona, pagou em duas semanas sua dívida com a dona do clube que a levou para lá. Embora tenha conseguido mudar para um local de trabalho mais seguro, ela reclama expressamente que faz pouco dinheiro e também da exploração a que está sujeita. Ela manda dinheiro para a família no Brasil, está comprando uma casa e "ajudando" a irmã a ir pra Espanha.

A trajetória de Verônica, as condições institucionais e materiais que delimitam sua trajetória e suas "escolhas", o universo de relações e representações do qual ela faz parte dos dois lados do Atlântico, as percepções que tem de si própria - tudo isso levanta um tenso e complexo conjunto de dilemas sobre "autonomia e desigualdades de gênero". A crítica de mais de três décadas empreendida por teóricas e organizações feministas ao pensamento político tem mudado, para dizer o mínimo, os modos pelos quais noçôes políticas básicas, tais como indivíduo e igualdade, engendram modelos normativos de democracia. A começar pela oposição público/privado, a explicitação e a contestação das múltiplas fontes da desigualdade de gênero (em meio a outras fontes: as hierarquias intrafamiliares, a divisão do trabalho doméstico, a privatização das práticas de cuidado, o ideal hegemônico de amor monogâmico, o heterossexismo) trazem dilemas de difícil resposta para quem almeja cenários democráticos substantivos. Isso é de especial relevância para sociedades como as nossas, nas quais convivem igualdade e desigualdade e nas quais opera a "acomodação", no termo de Biroli, entre igualdade formal e desigualdades reais; enfim, nas quais "a ausência de barreiras formais ou de coerção não corresponde a possibilidades iguais de autodeterminação para os indivíduos" (pp. 31-32). A prostituição ocupa aí posição tensa, sempre a reorganizar e polarizar os feminismos de vários matizes, e é partindo dela que vou destacar a riqueza dos debates feministas em teoria política revisitados, ampliados e criticados pela autora. Mais propriamente, é a partir das posições da discussão recente a favor ou contra a regulamentação da prostituição no Brasil, e bastante atento às autointerpretações de Verôni$\mathrm{ca}$, que vou tentar lançar luz sobre a complexidade implicada na adesão e na crítica feminista ao ideal de autonomia.

Os debates ao redor da prostituição podem ser, grosso modo, resumidos a um par antagônico: abolicionistas e pró-regulamentação, para utilizar os termos de como cada parte classifica a outra. Se, aqui como alhures, esse debate é via de regra intenso, ele ganhou contornos dramáticos em tempos de Copa do Mundo (realizada no Brasil em 2014). Recentemente, uma feminista abolicionista (Faria, 2014) sublinha que, em vez "de promover os direitos e a autonomia econômica das mulheres, o [recente] projeto [de lei de regulamentação] visa suprir uma necessidade da indústria sexual, que juntamente com as grandes corporações, buscam utilizar o corpo das mulheres para faturar altos montantes em grandes eventos como a Copa". Em sentido oposto a esse, outra postura (Castilhos, 2014) vê na Copa uma sorte de pânico sexual: sob o pretexto de proteção das mulheres, as iniciativas nacionais assumem lógicas de higienização de espaços públicos, pois não atuam contra formas de cafetinagem, mas, antes, expulsando prostitutas de seus locais de trabalho visíveis. 
O abolicionismo é radical, leva tom autonomista e dois eixos. Critica a objetificação das mulheres (Faria, 2014): "a legalização da cafetinagem contribui para legitimar o sistema de exploração, mantendo as mulheres como objetos e não como cidadãs"; nesse sistema, "homens prostituidores [...] consideram que as mulheres são uma mercadoria". Por outro lado, ao enfatizar "classe e raça" e "os países ricos", sua ênfase recai na não escolha das formas interseccionadas de inserção na divisão sexual e internacional do trabalho. Nesses termos, a postura pró-regulamentação seria "liberal" porque "centrada no indivíduo e suas escolhas no mercado, sem levar em consideração as relações políticas e de poder envolvidas" fazendo "parece[r] que estamos em um mundo em que todas as mulheres têm todas as condições para 'escolher' entre ser médica, professora universitária, empregada doméstica, prostituta, advogada" (Faria, 2014).

$\mathrm{O}$ argumento abolicionista opera uma sinonimização entre prostituição e exploração, uma é já e sempre outra, realidade que outros ignoram ou separam. "Ao separar a prostituição da exploração sexual, o serviço sexual livre do serviço sexual forçado, há uma intenção de legitimar a prostituição como um serviço que pode ser comercializado" (Faria, 2014, s/p). A regulamentação serve a "homens prostituidores", que são os sujeitos desse "sistema de exploração", enquanto "mulheres prostituídas" ou "traficadas" são submetidas a ele. "Não moralista", essa intervenção faz uma "defesa da liberdade e autonomia" das mulheres, mesmo se, relativamente às prostitutas, estas não sejam citadas ou escutadas. No limite, o texto abolicionista inverte a lógica dos teóricos do contrato: neles, a capacidade moral das mulheres é-lhes atribuída e, posteriormente ao casamento, retirada; já no abolicionismo, as mulheres "prostituídas", isto é, forçadas à exploração sexual parecem ser de antemão menores, sendo apenas potencialmente agentes morais, pois não desfrutam ainda das condiçōes para fazer suas escolhas.

$\mathrm{O}$ ataque à prostituição é, em vários sentidos e não sempre convergentes, conexo a debates feministas sobre autonomia. Contra uma noção abstrata de indivíduo, a crítica feminista define como "problema central o que se passa antes que as preferências sejam expressas" (Biroli, p. 34, grifo no original).
Esse "antes" tem como correlato, no argumento abolicionista, a ênfase nas desigualdades operantes na divisão sexual e internacional do trabalho. Desse modo, o abolicionismo colocaria na conta da não escolha pela prostituição "[os] recursos efetivamente disponíveis no processo em que as preferências se definiram e as escolhas foram feitas, assim como as formas de socialização nesse processo" (p. 34). Fazendo o caminho inverso também seria possível informar uma postura abolicionista a partir de críticas à "livre-escolha" e ao consentimento voluntário, tal como a que segue. "As preferências expressas em escolhas feitas em condições (e diante de restriçôes) materialmente definidas conduzem-nos diretamente à análise do contexto de sua produção" (p. 92). Aqui a ênfase nos constrangimentos desfaz a naturalidade das opçôes "livremente" feitas se, e toda vez que, rareiam as opçóes.

Talvez resida aí uma das maiores mutações no debate recente sobre autonomia: a ideia de que a produção das preferências e escolhas "não é individual" (p. 57) se enraíza nas teorias que tratam da "autonomia relacional", tomada como "característica de agentes que são seres racionais, com sentimentos, criativos, desejantes, encarnados e emotivos; [teorias que] destacam os modos nos quais os agentes são tanto psíquica e internamente diferenciados, como socialmente distintos dos outros" (Mackenzie e Stoljar, 2000, p. 21). Se essa reconceituação veio a somar dimensões relevantes para o escrutínio da autonomia, foi um viés socioestrutural que se imprimiu na renovação da categoria - "padrões socialmente estruturados delimitam a autonomia"; "condiçôes estruturais para o exercício da autonomia” (pp. 60-61).

Tal viés, porém, não deve sobrepujar outra dimensão cara e fundamental à noção de autonomia, qual seja, a autodeterminação. Nesse sentido, retomando o debate pró e contra a regulamentação do trabalho sexual, teríamos de levar em conta a perspectiva seja das prostitutas organizadas em coletivos, seja da própria Verônica. E escutá-las não é qualquer tipo de condescendência ou paternalismo teórico; pelo contrário, trata-se de afirmar a autodeterminação como núcleo distintivo, e inseparável, de agentes autônomos e de contornar "o risco de, por meio da vitimização, ignorar as perspectivas 
das próprias mulheres, desconsiderando-as como indivíduos capazes de definir suas preferências e de realizar escolhas legítimas" (p. 114).

Verônica se sente explorada, mas não sexualmente explorada. Entre as mulheres entrevistadas por Piscitelli (2012, p. 295), "[a]lgumas consideravam exploração qualquer parte do dinheiro retido por outros do custo dos programas. Outras pensavam que a exploração só existia quando havia claro abuso financeiro através de deduções e retençōes excessivas. Verônica define claramente este segundo conceito de exploração, em termos de relações de trabalho". À diferença do modo pelo qual o abolicionismo sinonimiza prostituição e exploração, Verônica vive em sua experiência o peso dessa exploração laboral. Além de taxas abusivas, ela não foi previamente avisada que metade do seu lucro iria direto para o clube onde trabalhava - falta de informação que impede a autorreflexão para uma escolha (mais) autônoma, porquanto informada (Dworkin, [1988] 2008). Vistas pelas lentes de Verônica, essas formas de violência e exploração no trabalho a que está sujeita, bem como sua permanência aí, não podem ser compreendidas e sequer combatidas pela "dualidade entre coerção e livre-escolha” (p. 96). Para entendê-las e quiçá transformá-las, valeria retomar noções de um feminismo marxista, ou melhor, deslocar o foco "para o escrutínio crítico do 'sim', isto é, para uma análise crítica do consentimento das mulheres" (p. 114).

"As escravas...", diz Verônica, "aquelas são vítimas [...]. Essas garotas querem fugir [...] mesmo se elas têm que ser deportadas pra isso" (apud Piscitelli, p. 297). Mais uma vez, a autoidentificação de Verônica não coaduna com o aquilo que o abolicionismo imagina das mulheres "prostituídas" e "traficadas". Em outro momento, uma organização de prostitutas pró-regulamentação publicou sua opinião a respeito da produção estatal de "vítimas": "as brasileiras - particularmente as mais pobres e escuras - em trajetórias de deslocamento internacional [...] são vistas como 'vítimas' potenciais que necessitam da tutela do Estado e das ONGs antitráfico" (Davida, 2005, p.182). Se abolicionistas e prostitutas organizadas concordam quanto ao perfil interseccionado da prostituição, elas não estão de acordo sobre como entender e como atuar diante de tais dinâmicas. Para o que nos interessa, a perspectiva das prostitutas, individual e coletivamente, importa porque sugere nuances entre agenciamentos dentro desse universo em nada uniforme, a começar pela distinção entre exploração e prostituição. Importa ainda porque "não se pode suspender a legitimidade da avaliação que [elas] fazem de sua própria situação e das escolhas que sustentam" (Biroli, p. 130).

A esta altura, poderíamos voltar à ênfase abolicionista nos constrangimentos que contornam ou mesmo minam a autonomia das prostitutas. "Dá pra imaginar que as diferentes trajetórias (fuga de situações de abuso, pobreza, violência, autoritarismo) e rotinas (sexo com vários clientes, uso de drogas pra conseguir aguentar) das mulheres prostitutas sejam uma 'livre escolha'?" (Faria, 2014). A questão não precisa ser formulada nesses termos, pois há um rol muito mais matizado, complexo e dramático, entre os polos duma "escolha" deliberada e a total "exploração sexual", cuja tradução teórica seria a superação da antinomia entre "consentimento voluntário e subordinação" (pp. 96 ss.). A identificação nuançada e crítica desse rol me parece fundamental, sob pena de incorrer na criminalização das próprias "vítimas", como é o caso de Verônica, que "ajudou" a irmã com os recursos da viagem até a Espanha. Aos olhos da legislação brasileira, por ter apoiado financeiramente a irmã, Verônica seria considerada "vítima do tráfico e traficante ao mesmo tempo" (Piscitelli, 2012, p. 293).

Não há saídas fáceis para os dilemas que os feminismos puseram à teoria política. $\mathrm{O}$ caso das posições ao redor da prostituição, contrastadas com parte dos pressupostos e caminhos de Autonomia e desigualdades de gênero, mostra a complexidade desses desafios, prático e teórico.

Cabe, por fim, notar uma desavença e uma falta. Tal como mostram os eixos pró e contra a regulamentação, Biroli ganharia na interlocução com o debate antropológico nacional. Notar tal falta não é algo retórico, pois ela leva à desavença, assentada no recurso a noções como dominação masculina e doxa. Bourdieu foi ora criticado ora reabilitado pelos feminismos (Moi, 1991; Young, 2011), mas "a dominação masculina" viu na antropologia brasileira uma contundente crítica (Corrêa, 1999).

Autonomia e desigualdades de gênero é permeado pelo constante e tenso equacionamento entre 
condições (condicionantes, limites, restriçōes e afins) para o exercício da autonomia e o respeito à autodeterminação individual. É nutrindo essa tensão que Biroli (p. 96) questiona "se há consentimento genuíno, autonomamente definido, quando as preferências e as escolhas se definem em contextos assimétricos, em meio a relações de opressão e dominação". Para o mesmo sentido, e a quem queira pesquisar agency, ela indica (este é um ponto alto no livro) a noção de "agência imperfeita" (pp. 48 ss.), isto é, a ideia de que as preferências individuais se dão, não a despeito de constrangimentos sociais, mas através deles, de modo que um ou outro grupo de indivíduos não é "desviante", "dependente" ou "deficitário", mas que, tal como a divisão sexual do trabalho, tais constrangimentos modulam suas possibilidades e "escolhas".

A lógica explicativa subjacente à ideia de "dominação masculina" parece ir, porém, na contramão do esforço teórico de Autonomia e desigualdades de gênero. Tal esforço é visível, por exemplo, no diagnóstico de Biroli (p. 86), que, ressoando Young, afirma: "a dominação não totaliza as experiências". Além de criticar Bourdieu pela transposição da lógica cabila para as sociedades ocidentais, Corrêa critica seu desdém ao acúmulo de reflexão feminista e também sua lógica totalizante, mostrando que as "estratégias inconscientes" inscritas no habitus de qualquer ator que não esteja na posição de homem branco... estão destinadas a reproduzir estruturas de dominação. Feministas são exemplo disso: tão "contaminadas [que estão] pela lógica da dominação masculina que suas análises são simples réplicas do mesmo esquema classificatório de sempre" (idem, p. 47). Já "os homossexuais [se] são 'viris' é porque incorporaram 'disposiçōes' do habitus dominante [...]. Não há como escapar [...] do habitus dominante - tautologicamente, ele domina sempre" (Corrêa, 1999, p. 50). Maldito e predito, o mundo da dominação masculina não tem espaço para agency ou, no máximo, ela é totalizada e tautológica.

Há ainda o recurso ao "efeito de doxa", isto é, ao "[suposto] reconhecimento do mundo a partir das categorias [sexistas] que esse mundo tornou disponível" (p. 84). Os dilemas levantados por Biroli ao longo do livro demandam um suporte público de vocalização e tematização para que sejam objeto de justificação ampla e eventual transformação. "A violência doméstica e o estupro no casamento, por exemplo, dependem de que sejam tornados públicos para que a integridade física e a privacidade enquanto autonomia decisional sejam garantidas" ( $\mathrm{p}$. 123 , grifo no original). Ora, a teorização de Bourdieu não conta com um nível de análise próprio às trocas públicas nas quais indivíduos e grupos disputam, e não só reproduzem (Alexander, 1995) categorias e discursos por meio de relaçôes assimétricas entre si e vis-à-vis o Estado. Um diagnóstico da formação de preferências que reproduzem a ortodoxia de mundos e lógicas (masculinistas, heterossexistas, racistas ou outras) de dominação só está completo, só é realmente crítico, se e porquanto for capaz de reconstruir as condições coletivas de crítica individual a esses mesmos mundos (Boltanski e Thévenot, 2006) - tarefa incontornável, a meu ver, a qualquer contribuição de estofo crítico democrático que aproxime, e não afaste, dominação e autonomia. Essa desavença é pontual e, embora tenha função tangencial na obra de Biroli, o recurso à dominação masculina como uma sorte de novo clássico (anti)feminista tem infelizmente ganhado peso em nosso escasso debate sobre desigualdades de gênero e democracia (Marques e Montezuma, 2014).

No seu todo, o mérito de Autonomia e desigualdades de gênero é duplo: expõe o alcance político de parte das ciências sociais brasileiras e dá também pista da relevância dos feminismos para nossa ciência política.

\section{BIBLIOGRAFIA}

ALEXANDER, J. (1995), "The reality of reduction: the failed synthesis of Pierre Bourdieu", in J. Alexander, Fin de siècle social theory. Nova York/Londres, Verso.

BOLTANSKI, L. \& THÉVENOT, L. (2006), On justification: economies of worth. Princeton/ Oxford, Princeton University Press.

CASTILHOS, W. (2014), "O pânico moral da Copa”. Disponível em www.clam.org.br/destaque/conteudo.asp?cod=11619, consultado em 30 jun. 2014. 
CORRÊA, M. (1999), "O sexo da dominação". Novos Estudos Cebrap, 54: 43-53.

DAVIDA (GRUPO). (2005), "Prostitutas, 'traficadas' e pânicos morais: uma análise da produção de fatos em pesquisas sobre o 'tráfico de seres humanos". Cadernos Pagu, 25: 153-184.

DWORKIN, G. (1998 2008), The theory and practice of autonomy. Nova York, Cambridge University Press.

FARIA, N. (2014). "A quem serve a regulamentação da prostituição?”. Disponível em http:// br.boell.org/pt-br/2014/05/10/quem-serve-regulamentacao-da-prostituicao, consultado em 30 jun. 2014.

MACKENZIE, C. \& STOLJAR, N. (2000), "Autonomy refigured", in C. Mackenzie e N. Stoljar (eds.), Relational autonomy: feminist perspectives on autonomy, agency, and the social self, Nova York/Oxford, Oxford University Press.

MARQUES, D. \& MONTEZUMA, I. (2014), "Desigualdades de gênero e democracia: como as ciências sociais brasileiras (não) trabalham com o tema". Trabalho apresentado no $38^{\circ}$ Encontro Anual da Anpocs, Caxambu.

MOI, T. (1991), "Appropriating Bourdieu”. New Literary History, 22: 1017-1049.

PISCITELLI, A. (2012), "Revisiting notions of sex trafficking and victims". Vibrant, 9: 275-310.

YOUNG, I. (2011), Responsibility for justice. Oxford, Oxford University Press.

JOSÉ SZWAKO é professor do Instituto de Estudos Sociais e Políticos da Universidade do Estado do Rio de Janeiro (Iesp-Uerj). E-mail: zeszwako@iesp.uerj.br.

DOI: http//dx.doi.org/10.17666/3089182-186/2015

\section{Por uma teoria alternativa do campesinato nas fronteiras do capitalismo}

Francisco de Assis Costa. Economia camponesa nas fronteiras do capitalismo: teoria e prática nos EUA e na Amazônia brasileira. Belém, Naea/UFPA, 2012. 310 páginas.

\section{Luiz Cláudio Moreira Melo Jr.}

Francisco de Assis Costa (nascido em 1948) é professor do Núcleo de Altos Estudos Amazônicos da Universidade Federal do Pará (Naea/UFPA) desde 1989. Doutorou-se em 1988 em economia pela Freie Universität Berlin, Alemanha. Coordena o grupo de pesquisa Dinâmica Agrária e Desenvolvimento Sustentável na Amazônia, que há anos vem desenvolvendo estudos que compõem uma ampla abordagem interdisciplinar da Amazônia. É autor de diversas obras de referência sobre dinâmica agrária e campesinato na Amazônia, entre elas: Ecologismo e questão agrária na Amazônia (Naea/UFPA, 1992), Grande capital e agricultura na Amazônia: a experiência Ford no Tapajós (Naea/UFPA, 1993) e Formação agropecuária da Amazônia: os desafios do desenvolvimento sustentável (Naea/UFPA, 2000). Recentemente, a produção do seu grupo de pesquisa tem sido organizada e divulgada em cinco séries temáticas, contando com o lançamento de títulos inéditos, como é o caso da obra aqui resenhada, além de reedições de obras anteriores. A obra Economia camponesa nas fronteiras do capitalismo é o volume 1 da série II, denominada Fundamentos Teóricos e Metodológicos.

Eu sintetizaria assim a temática desse novo livro de Francisco de Assis Costa: trata-se da construção das bases teórico-metodológicas da teoria do investimento camponês como uma proposta alternativa ao entendimento do campesinato nas fronteiras do capitalismo. A teoria é defendida tanto para a fronteira mais intensiva do sistema (campesinato americano), como para a sua fronteira mais extensiva (campesinato amazônico), mostrando a eficiência reprodutiva e a capacidade de permanência da economia em bases camponesas.

$\mathrm{O}$ autor fundamenta as suas análises utilizando dados secundários dos Censos dos Estados Unidos 